\title{
Analisis Sentimen untuk Mengetahui Kelemahan dan Kelebihan Pesaing Bisnis Rumah Makan Berdasarkan Komentar Positif dan Negatif di Instagram
}

\author{
Veronica Ambassador Flores ${ }^{1}$, Lie Jasa ${ }^{2}$, Linawati $^{3}$ \\ Submission: 11-02-2020, Accepted:24-03-2020
}

\begin{abstract}
Formulating a marketing strategy for a pioneering or long-running restaurant business is a very important thing. Analyze the weaknesses or strengths of business competitors is one of these strategies. Identification of weaknesses and strengths can be done by taking data from comments on competitors' Instagram accounts using Text Preprocessing Techniques. Text Preprocessing is a text processing algorithm, consisting of Transform Cases, Stopword Filters, Tokenize Filters, and Stemming. Instagram is one of the most widely used social media accounts as a promotional media in Indonesia. Another method that can be used is Full Text Search, this method can analyze the patterns in comments that have been parsed for classified into positive, negative, or neutral sentiment categories. This study concludes that this sentiment analysis system can automatically recognized weaknesses (based on negative comments) and strengths (based on positive comments) based on comments on Instagram accounts owned by restaurant business competitors with an accuracy of $85 \%$ and a precision value of $79 \%$.
\end{abstract}

Keywords - Sentiment Analysis, Word Dictionary, Full Text Search, Pattern Matching, Instagram

Intisari-Merumuskan strategi pemasaran bagi bisnis rumah makan yang baru merintis ataupun sudah berjalan lama merupakan hal yang sangat penting untuk dilakukan. Menganalisis kelemahan maupun kelebihan pesaing bisnis termasuk salah satu strategi tersebut. Identifikasi kelemahan dan kelebihan dapat dilakukan dengan mengambil data dari komentar-komentar yang ada pada akun Instagram pesaing, dengan menggunakan Teknik Text Preprocessing. Text Preprocessing adalah algoritma pemrosesan teks, yang terdiri dari tahap Transform Cases, Filter Stopword, Filter Tokenize, dan Stemming. Instagram sendiri merupakan salah satu akun sosial media yang paling banyak digunakan sebagai salah satu media promosi di Indonesia. Metode lainnya yang dapat digunakan adalah Full Teks Search, metode ini dapat menganalisis pola yang terdapat pada komentar yang sudah di parsing untuk kemudian diklasifikasikan kedalam kategori sentimen positif, negatif, ataupun netral. Penelitian ini menyimpulkan bahwa sistem analisis sentimen ini dapat mengenali kelemahan (berdasarkan komentar negatif) dan kelebihan (berdasarkan komentar positif) secara otomatis dengan baik berdasarkan komentar pada akun Instagram milik pesaing bisnis rumah makan dengan hasil akurasi sebesar $85 \%$ dan nilai presisi sebesar79 \%

\footnotetext{
${ }^{1}$ Mahasiswa,Magister Teknik Elektro Universitas Udayana Gedung Pascasarjana Universitas Udayana, Jl.PB Sudirman Denpasar-Bali 80234 INDONESIA (tlp:0361-555225; e-mail: veronicaambassador@gmail.com)

${ }^{2,}{ }^{3}$ Staff Prngajar,Magister Teknik Elektro Universitas Udayana Gedung Pascasarjana Universitas Udayana, Jl. PB Sudirman Denpasar-Bali 80234 INDONESIA (tlp: 0361-555225; e-mail: liejasa@unud.ac.id; linawati@unud.ac.id)
}

Kata Kunci-Analisis Sentimen, Kamus Kata, Full Text Search, Pattern Matching, Instagram

\section{Pendahuluan}

Rumah makan di daerah Denpasar sudah sangat banyak jumlahnya lengkap dengan menu yang beraneka ragam. Salah satu strategi yang digunakan oleh pemilik usaha untuk tetap menstabilkan bisnis yang sedang dijalankan yaitu dengan melakukan promosi. Perumusan strategi pemasaran untuk promosi dapat mempertimbangkan berbagai faktor, salah satunya yaitu mengetahui kelemahan maupun kelebihan dari para pesaing bisnis [1].

Identifikasi pesaing dapat dengan mudah dilakukan degan bantuan teknologi. Sistem analisis sentimen merupakan sistem yang dapat mengidentifikasikan opini secara otomatis sehingga mendapatkan informasi dari sumber yang berupa teks [2], [3]. Opini yang dijadikan sebagai objek penelitian akan dikumpulkan melalui komentar pada sosial media Instagram, hal ini dikarenakan Instagram merupakan salah satu media sosial yang paling banyak digunakan di Indonesia. Berdasarkan survei yang dilakukan oleh NapoleonCat pada Januari 2019, Indonesia menduduki posisi ke-4 sebagai pengguna Instagram terbanyak di Indonesia. Total pengguna sosial Media Instagram terhitung sebanyak 61.610 .000 pengguna atau sebesar $22.6 \%$ dari total populasi di Indonesia [4]. Instagram memungkin pengguna untuk meninggalkan tanda suka maupun komentar pada foto yang diunggah di platform ini. Komentar yang ditinggalkan pengguna dapat diidentifikasi dengan pendekatan Full Text Search. Pendekatan ini terdiri dari kueri pencarian yang digunakan untuk mencari kecocokan yang paling relevan antara dua buah string, sehingga string dapat diidentifikasi kedalam tiga golongan, yaitu positif, negatif, dan netral [5], [6].

Penelitian [7] mengatakan bahwa sistem analisis sentimen dapat digunakan untuk mengetahui opini masyarakat di Bali terhadap Calon Gubernur dan Wakil Gubernur Bali pada periode 2018, dengan tingkat akurasi sebesar $89 \%$.

Penelitian [8] menggunakan media sosial Facebook dalam melakukan analisis sentimen berbahasa Indonesia dengan menggunakan metode klasifikasi Naive Bayes. Penelitian ini mengatakan bahwa semakin banyak data yang diuji kan, maka tingkat akurasinya akan semakin tinggi.

Penelitian [9] menyimpulkan bahwa identifikasi sentimen akan lebih akurat jika ditambahkan dengan sinonim atau padanan kata, seperti kata 'bagus' dengan sinonim 'apik' dimasukkan kedalam rating positif.

Penelitian [6] menggunakan Full Text Search Boolean Mode sebagai metode pencocokan pola pada engine chatbot 
informasi objek wisata di Bali. Metode ini dapat bekerja dengan baik karena data mengenali 19 pertanyaan dari total 25 pertanyaan yang diajukan.

Berdasarkan latar belakang tersebut, maka tujuan utama dari penelitian ini yaitu membahas mengenai implementasi sistem analisis sentimen untuk memprediksi kekurangan dan kelebihan dari bisnis kuliner di daerah Denpasar melalui media sosial Instagram menggunakan pendekatan Full Text Search.

\section{LANDASAN TEORI}

Penelitian ini dilandasi oleh beberapa teori pendukung yang berasal dari berbagai sumber.

\section{A. Analisis Sentimen Berdasarkan Kamus Kata}

Analisis Sentimen merupakan proses untuk mencari makna dari sebuah pandangan, pendapat atau emosi yang terdapat pada sebuah teks, ucapan, post (aktivitas di Internet), atau basis data dengan pendekatan Natural Language Processing (NLP). Analisis sentimen terbagi kedalam beberapa tugas yang diantaranya yaitu, ekstraksi sentimen, klasifikasi sentimen, dan deteksi spam [10]. Analisis sentimen sangat berguna dalam menjalankan sebuah bisnis guna mengetahui bagaimana reaksi pelanggan terhadap produk yang dijual [11].

Dasar yang dipakai dalam menganalisis sentimen pada sebuah teks adalah dengan membangun sebuah kamus kata yang terdiri dari kata positif dan kata negatif berdasarkan sifat dari kata itu sendiri. Tingkat akurasi pada pendekatan ini bergantung dari seberapa lengkap kamus kata yang dibangun [12].

\section{B. Text Mining}

Text Mining merupakan sebuah algoritma dalam mencari sebuah informasi dari sebuah teks yang terstruktur. Text Mining juga dapat membantu pengguna untuk mengetahui isi dari sebuah bacaan tanpa harus membaca semua isi dari bacaan tersebut. Pengelolaan sumber data pada Text Mining dilakukan dalam beberapa tahapan. Tahapan ini dikenal dengan istilah Text Preprocessing. Text Preprocessing terdiri dari beberapa tahapan, yaitu Transform Cases, Filter Stopword, dan Filter Tokenize, dan Stemming [13].

\section{Full Text Search}

Full Text Search merupakan metode pencocokan pola yang diimplementasikan pada fungsi bawaan pada MySQL dengan bentuk kueri Match (...) Against (...) guna mencocokkan dua buah string sehingga memberikan hasil yang paling relevan. Full Text Search bekerja dengan mencocokan string yang ada pada klausa Match terhadap string yang ada pada basis data di klausa Against [5].

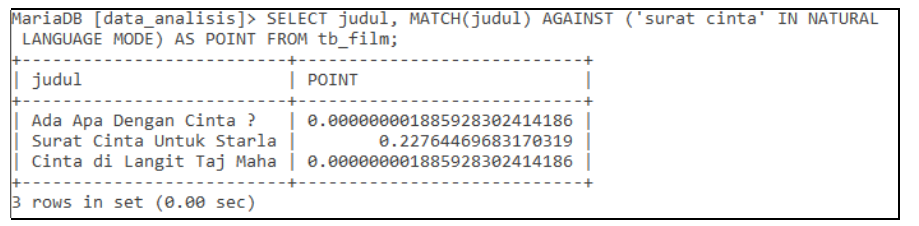

Gambar 1: Kueri Full Text Search pada MySQL
Gambar 1 menampilkan kueri Full Text Search yang dapat memberikan nilai relevansi kemiripan antara string dan data yang ada pada basis data.

\section{D. $T F-D F$}

TF-IDF merupakan algoritma paling umum yang biasa digunakan dalam perhitungan bobot suatu kata terhadap dokumen [14].

Term Frequency (TF) digunakan untuk mengukur seberapa sering sebuah kata muncul pada suatu dokumen. Inverse Document Frequency (IDF) berguna untuk memberikan bobot yang paling kecil bagi kata dengan frekuensi kemunculan terbanyak, dan memberikan bobot terbesar bagi kata yang frekuensi kemunculannya paling jarang. Hal ini dikarenakan algoritma $T F-I D F$ menganggap bahwa semakin sedikit tingkat frekuensi kemunculan kata pada sebuah dokumen maka kata tersebut akan dianggap semakin unik atau penting [15].

\section{E. Instagram}

Instagram adalah platform sosial media yang memungkinkan penggunanya untuk berbagi foto, mengambil gambar, menerapkan filter pada gambar dan membagikan gambar-gambar tersebut dalam beberapa cara, termasuk mengintegrasikannya dengan jejaring sosial seperti Twitter dan Facebook. Interaksi yang dapat dilakukan pengguna dalam Instagram antara lain memberikan tanda suka dan komentar pada gambar yang diunggah di Instagram, serta saling berkirim pesan berupa text, gambar, maupun video. Fitur lainnya terkait komentar pada Instagram yaitu pengguna dapat membatasi komentar yang dianggap tidak pantas atau tidak perlu pada gambar yang diunggah. Top comment juga merupakan fitur yang akan menampilkan komentar yang paling banyak disukai oleh para pengguna, sehingga komentar tersebut akan muncul di paling atas daftar komentar.

Indonesia sendiri menduduki posisi ke-4 sebagai negara dengan pengguna Instagram terbanyak, dimana diatas Indonesia masih terdapat negara Amerika Serikat, Brasil, dan India. Terhitung pengguna Instagram pada November 2019 mencapai 61.610 .000 pengguna atau $22.6 \%$ dari populasi penduduk di Indonesia [4].

\section{METODE PENELITIAN}

Metode yang digunakan dalam perancangan dan implementasi dari analisis sentimen ini antara lain: 


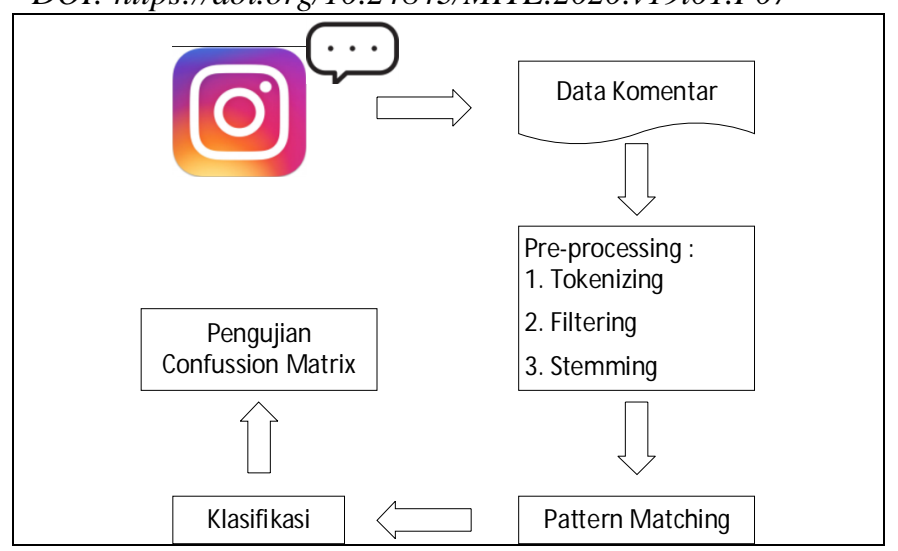

Gambar 2: Gambaran Umum Sistem

Cara kerja dari sistem "Analisis Sentimen untuk Mengetahui Kelemahan dan Kelebihan Pesaing Bisnis Rumah Makan Berdasarkan Komentar Positif dan Negatif di Instagram" adalah sebagai berikut:

\section{A. Data Penelitian}

Data penelitian diambil melalui komentar-komentar pengguna Instagram pada akun Instagram rumah makan yang dianggap sebagai pesaing. Data diambil dari 5 rumah makan terpopuler yang berada di daerah Denpasar.

\section{B. Text Preprocessing}

Komentar yang sudah dikumpulkan akan melalui proses Text Preprocessing, proses ini berguna untuk membuang atribut yang dianggap tidak perlu pada sebuah paragraf/kalimat/kata. Tahapan Text Preprocessing yaitu :

1) Tokenizing: tahapan ini berguna untuk menghapus tanda baca dan memisahkan tiap kata berdasarkan indeks spasi.

2) Filtering: tahapan ini terdiri dari dua tahapan yaitu, menghilangkan semua karakter angka pada text, dan menghapus kata yang dianggap tidak perlu atau tidak bermakna dari kamus kata stopword.

3) Stemming: tahapan ini memproses tiap indeks kata dengan mengubahnya menjadi kata dasar.

\section{Pattern Matching}

Pattern Matching merupakan algoritma yang biasa digunakan untuk melakukan pencocokan antara sebuah pola dengan pola lainnya yang ingin dibandingkan [16]. Metode Pattern Matching yang digunakan adalah Full Text Search, dimana tiap indeks kata pada tiap komentar akan dicocokkan dengan kamus kata yang sudah diklasifikasikan sesuai sentimennya (positif/negatif).

Tabel 1 menampilkan kamus kata yang mengkategorikan setiap kata yang berhubungan dengan penilaian pada makanan kedalam kategori positif dan negatif.
TABEL 1

KAMUS KATA POSITIF/NEGATIF

\begin{tabular}{|c|l|l|}
\hline No & \multicolumn{1}{|c|}{ Kata } & \multicolumn{1}{c|}{ Kategori } \\
\hline 1 & Ajib & Positif \\
\hline 2 & Aneh & Negatif \\
\hline 3 & Bau & Negatif \\
\hline 4 & Bersih & Positif \\
\hline 5 & Doyan & Positif \\
\hline 6 & Enak & Positif \\
\hline 7 & Favorite & Positif \\
\hline 8 & Kotor & Negatif \\
\hline 9 & Mahal & Negatif \\
\hline 10 & Manis & Positif \\
\hline 11 & Murah & Positif \\
\hline 12 & Ramah & Positif \\
\hline 13 & Ramai & Positif \\
\hline 14 & Tidak & Negatif \\
\hline 15 & Wangi & Positif \\
\hline & $\ldots$ & $\ldots$ \\
\hline
\end{tabular}

\section{Klasifikasi Rule Based Method}

Rule Based Method merupakan salah sau metode klasifikasi yang mengelompokkan suatu kelas berdasarkan peraturan (rule) tertentu. Metode ini didefinisikan menggunakan klausa IF (kondisi) THEN (solusi). Berikut aturan yang akan dipakai dalam menentukan kelas sentimen pada penelitian ini :

- Jika kata bersentimen positif lebih banyak dari kata bersentimen negatif, maka komentar tersebut akan digolongkan kedalam kelas positif.

- Jika kata bersentimen negatif lebih banyak dari kata bersentimen positif, maka komentar tersebut akan digolongkan kedalam kelas negatif.

- Jika kata bersentimen positif berjumlah sama dengan kata bersentimen negatif, maka komentar tersebut akan digolongkan kedalam kelas netral.

- Jika tidak terdapat kata bersentimen positif maupun negatif, maka komentar tersebut akan digolongkan kedalam kelas netral.

\section{IV.PEMBAHASAN DAN ANALISIS SiSTEM}

Penelitian "Analisis Sentimen untuk Mengetahui Kelemahan dan Kelebihan Pesaing Bisnis Rumah Makan Berdasarkan Komentar Positif dan Negatif di Instagram” diharapkan dapat mengenali sentimen suatu komentar dengan akurat.

\section{A. Data Penelitian}

Data komentar berjumlah 177 data yang diambil dari 5 akun Instagram tempat makan yang berada di daerah Denpasar, yaitu TM 1, TM 2, TM 3, TM 4, dan TM 5.

\section{B. Text Preprocessing}

Tahapan Text Preprocessing pada komentar Instagram: 
1) Tokenizing: Tabel 2 menampilkan perbandingan komentar asli dan komentar yang sudah melewati tahap Tokenizing.

TABEL 2

PROSES TOKENIZING

\begin{tabular}{|c|c|c|}
\hline No & Komentar Asli & $\begin{array}{c}\text { Komentar setelah } \\
\text { Tokenizing }\end{array}$ \\
\hline 1 & $\begin{array}{l}\text { Bumbunya tidak enak kayak } \\
\text { tepung. }\end{array}$ & $\begin{array}{l}\text { Bumbunya tidak enak } \\
\text { kayak tepung }\end{array}$ \\
\hline 2 & $\begin{array}{l}\text { @ dewik_18 akhirnya, kirain } \\
\text { sy doang yg gak doyan, } \\
\text { manis thok rasanya }\end{array}$ & $\begin{array}{l}\text { dewik_18 akhirnya kirain } \\
\text { sy doang yg gak doyan, } \\
\text { manis thok rasanya }\end{array}$ \\
\hline 3 & $\begin{array}{l}\text { Baru kemarin makan disini } \\
\text { kak, porsinyaa ajib } \\
\text { @deliciousbali } \odot\end{array}$ & $\begin{array}{l}\text { Baru kemarin makan disini } \\
\text { kak, porsinyaa ajib } \\
\text { deliciousbali }\end{array}$ \\
\hline 4 & Blm ada di gofood ya, Min? & Blm ada di gofood ya, Min \\
\hline 5 & $\begin{array}{l}\text { Favorite kita@gustitiksa } \\
\text { 'b! }\end{array}$ & Favorite kita gustitiksa \\
\hline
\end{tabular}

2) Filtering: Tabel 3 menampilkan perbandingan komentar yang sudah melewati proses Tokenizing dan komentar yang sudah melewati tahap Filtering.

TABEL 3

PROSES FILTERING

\begin{tabular}{|c|l|l|}
\hline No & \multicolumn{1}{|c|}{$\begin{array}{c}\text { Komentar setelah } \\
\text { Tokenizing }\end{array}$} & Komentar setelah Filtering \\
\hline 1 & $\begin{array}{l}\text { Bumbunya tidak enak kayak } \\
\text { tepung }\end{array}$ & $\begin{array}{l}\text { bumbunya tidak enak kayak } \\
\text { tepung }\end{array}$ \\
\hline 2 & $\begin{array}{l}\text { dewik_18 akhirnya kirain sy } \\
\text { doang yg gak doyan, manis } \\
\text { thok rasanya }\end{array}$ & $\begin{array}{l}\text { dewik_18 akhirnya kirain sy } \\
\text { doang yg gak doyan manis } \\
\text { thok rasanya }\end{array}$ \\
\hline 3 & $\begin{array}{l}\text { Baru kemarin makan disini } \\
\text { kak, porsinyaa ajib } \\
\text { deliciousbali }\end{array}$ & $\begin{array}{l}\text { baru kemarin makan disini } \\
\text { kak porsinyaa ajib } \\
\text { deliciousbali }\end{array}$ \\
\hline 4 & Blm ada di gofood ya, Min & blm ada gofood min \\
\hline 5 & Favorite kita gustitiksa & favorite gustitiksa \\
\hline
\end{tabular}

3) Stemming: Tabel 4 menampilkan perbandingan komentar yang sudah melewati proses Filtering dan komentar yang sudah melewati tahap Stemming.

TABEL 4

PROSES STEMMING

\begin{tabular}{|c|l|l|}
\hline No & Komentar setelah Filtering & \multicolumn{1}{c|}{$\begin{array}{c}\text { Komentar setelah } \\
\text { Stemming }\end{array}$} \\
\hline 1 & $\begin{array}{l}\text { bumbunya tidak enak kayak } \\
\text { tepung }\end{array}$ & $\begin{array}{l}\text { bumbu tidak enak kayak } \\
\text { tepung }\end{array}$ \\
\hline 2 & $\begin{array}{l}\text { dewik_18 akhirnya kirain sy } \\
\text { doang yg gak doyan manis } \\
\text { thok rasanya }\end{array}$ & $\begin{array}{l}\text { dewik18 akhir kirain sy } \\
\text { doang yg gak doyan manis } \\
\text { thok rasa }\end{array}$ \\
\hline$\cdot$ & $\begin{array}{l}\text { baru kemarin makan disini } \\
\text { kak porsinyaa ajib } \\
\text { deliciousbali }\end{array}$ & $\begin{array}{l}\text { baru kemarin makan sini kak } \\
\text { porsinyaa ajib deliciousbali }\end{array}$ \\
\hline 4 & blm ada gofood min & blm ada gofood min \\
\hline 5 & favorite gustitiksa & favorite gustitiksa \\
\hline
\end{tabular}

\section{Pattern Matching}

Komentar yang sudah melewati tahap Text Preprocessing kemudian dicocokkan dengan kamus kata yang sudah dibangun dengan menggunakan kueri Full Text Search di MySQL.

p-ISSN:1693 - 2951; e-ISSN: 2503-2372
TABEL 5

PATTERN MATCHING

\begin{tabular}{|l|l|l|l|}
\hline No & \multicolumn{1}{|c|}{ Komentar } & \multicolumn{2}{|c|}{ Hasil } \\
\hline \multirow{3}{*}{1} & \multirow{3}{*}{ bumbu tidak enak kayak tepung } & Tidak & Negatif \\
\cline { 3 - 4 } & & Tidak & Negatif \\
\cline { 3 - 4 } & \multirow{4}{*}{2} & Enak & Positif \\
\hline \multirow{2}{*}{2} & \multirow{2}{*}{$\begin{array}{l}\text { dewik18 akhir kirain sy doang yg } \\
\text { gak doyan manis thok rasa }\end{array}$} & Manis & Positif \\
\cline { 3 - 4 } & & Doyan & Positif \\
\cline { 3 - 4 } & & Unjuk rasa & Negatif \\
\cline { 3 - 4 } & & gak & Negatif \\
\cline { 3 - 4 } & & gak & Negatif \\
\hline 4 & blm ada gofood min & Ajib & Positif \\
\hline 5 & favorite gustitiksa & Blm & Negatif \\
\hline
\end{tabular}

\section{Klasifikasi Rule Based Method}

Tabel 6 menunjukkan hasil pengklasifikasian dari aturan (rule) yang sudah ditetapkan.

TABEL 6

HASIL KLASIFIKASI

\begin{tabular}{|c|l|c|c|}
\hline No & \multicolumn{1}{|c|}{ Komentar Asli } & Prediksi & Aktual \\
\hline 1 & $\begin{array}{l}\text { Bumbunya tidak enak kayak } \\
\text { tepung. }\end{array}$ & Negatif & Kelemahan \\
\hline 2 & $\begin{array}{l}\text { @ dewik_18 akhirnya, kirain sy } \\
\text { doang yg gak doyan, manis } \\
\text { thok rasanya }\end{array}$ & Negatif & Kelemahan \\
\hline 3 & $\begin{array}{l}\text { Baru kemarin makan disini } \\
\text { kak, porsinyaa ajib } \\
\text { @ deliciousbali @-) }\end{array}$ & Positif & Kelebihan \\
\hline 4 & Blm ada di gofood ya, Min? & Negatif & Kelemahan \\
\hline 5 & Favorite kita @ gustitiksa & Positif & Netral \\
\hline
\end{tabular}

Hasil klasifikasi dari 177 data komentar menghasilkan 25 komentar positif, 18 komentar negatif, dan 124 komentar netral.

\section{E. Pengujian Confussion Matrix}

Kinerja sistem dapat diukur dengan menghitung nilai accuracy, recall dan precision nya. Nilai accuracy diperoleh dengan membandingkan jumlah seluruh data prediksi dengan jumlah data klasifikasi yang sebenarnya. Recall diperoleh dengan membandingkan jumlah data hasil klasifikasi yang relevan dan total data yang dianggap relevan. Sedangkan precision diperoleh dengan membandingkan jumlah data hasil klasifikasi yang relevan dan total jumlah data yang ditemukan pada kelas tertentu.

Untuk menghitung nilai recall dan precision, kita bisa menggunakan confussion matrix seperti yang ditunjukkan oleh Tabel 7. Dalam confussion matrix dikenal beberapa istilah yang harus diketahui, yakni

1) TP (True Positive): yakni kelas yang diprediksi positif dan hasilnya dikategorikan sebagai "kelebihan" dari pesaing.

2) $T N$ (True negatif): yakni kelas yang diprediksi negatif dan hasilnya dikategorikan sebagai "kekurangan" dari pesaing.

3) TN (True netral): yakni kelas yang diprediksi netral dan hasilnya netral.

Veronica Ambassador Flores: Analisis Sentimen untuk Mengetahui ... 
4) FP (False Positive): yakni kelas yang diprediksi positif tetapi hasilnya dikategorikan sebagai "kekurangan" dari pesaing.

5) FP (False Positive): yakni kelas yang diprediksi positif tetapi hasilnya dikategorikan netral

6) FN (False negatif): yakni kelas yang diprediksi negatif tetapi hasilnya dikategorikan sebagai "kelebihan" dari pesaing.

7) FN (False negatif): yakni kelas yang diprediksi negatif tetapi hasilnya netral.

8) FN (False netral): yakni kelas yang diprediksi netral tetapi hasilnya dikategorikan bukan sebagai "kelebihan" dari pesaing.

9) FN (False netral): yakni kelas yang diprediksi netral tetapi hasilnya dikategorikan bukan sebagai "kekurangan" dari pesaing.

TABEL 7

CONFUSSION MATRIX

\begin{tabular}{|c|c|c|c|c|}
\hline & \multicolumn{3}{|c|}{ Kelas Predikat } \\
\hline & & Positif & Negatif & Netral \\
\hline \multirow{3}{*}{ Kelas Aktual } & Kelebihan & 26 & 1 & 6 \\
\hline & Kekurangan & 2 & 10 & 2 \\
\hline & Netral & 7 & 7 & 116 \\
\hline
\end{tabular}

Tabel 7 menunjukkan bahwa komentar yang berhasil dikenali sebagai komentar positif dan komentar tersebut adalah benar sebagai kelebihan dari pesaing berjumlah 26 komentar dari total 35 komentar positif, sedangkan komentar yang berhasil dikenali sebagai komentar negaif dan komentar tersebut adalah benar sebagai kekurangan dari pesaing berjumlah 10 komentar dari total 18 komentar negatif. Persamaan 1 dan Persamaan 2 menunjukkan perhitungan akurasi dan presisi dari hasil prediksi kelas komentar oleh sistem dengan kelas aktualnya.

Iccuracy $=\frac{(\text { TPositif }+ \text { TNegatif }+ \text { TNetral })}{(\text { jumlah data keseluruhan })} \times 100 \%$

Accuracy $=\frac{(152)}{(177)} \times 100 \%$

Accuracy $=85 \%$

'recision $=\frac{(\text { TPositif })}{(\text { True Positif }+ \text { False Positif })} \times 100 \%$

Precision $=\frac{(26)}{(33)} \times 100 \%$

Veronica Ambassador Flores: Analisis Sentimen untuk Mengetahui...
Precision $=79 \%$

Dari perhitungan Persamaan 1 dan 2, dapat dilihat bahwa tingkat akurasi dari sistem analisis sentimen ini dapat bekerja dengan baik dengan tingkat akurasi sebesar 85\%. Komentar relevan dapat dikenali dengan baik, dengan tingkat presisi sebesar 79\% (Persamaan 2).

Dengan tingkat akurasi dan presisi tersebut, maka dapat disimpulkan bahwa sistem analisis sentimen dengan menggabungkan metode Text Preprocessing, Full Teks Search, dan Rule Based dapat mengenali kelemahan pesaing secara otomatis dengan mengklasifikasikan komentar yang ada pada akun Instagram pesaing ke dalam kategori negatif. Sistem juga dapat mengetahui kelebihan dari tempat makan milik pesaing dengan mengidentifikasi komentar positif yang ada pada akun Instagram tersebut.

\section{KesIMPUlAN}

Berdasarkan hasil ujicoba dari penelitian "Analisis Sentimen untuk Mengetahui Kelemahan dan Kelebihan Pesaing Bisnis Rumah Makan Berdasarkan Komentar Positif dan Negatif di Instagram" dapat disimpulkan penelitian ini dapat digunakan untuk mengidentifikasi kelemahan (dari komentar negatif) dan kelebihan (dari komentar positif) dari pesaing bisnis dengan tingkat akurasi sebesar $85 \%$ dan nilai presisi sebesar $79 \%$.

\section{REFERENSI}

[1] A. Y. Adom, I. K. Nyarko and G. N. K. Som, "Competitor Analysis in Strategic Management: Is it a Worthwhile Managerial Practice in Contemporary Times?," Journal of Resources Development and Management, vol. 24, 2016.

[2] I. Zulfa and E. Winarko, "Sentimen Analisis Tweet Berbahasa Indonesia dengan Deep Belief Network," IJCCS, vol. 11, no. 2, 2017.

[3] B. Gunawan, H. S. Pratiwi and E. E. Pratama, "Sistem Analisis Sentimen pada Ulasan Produk Menggunakan Metode Naive Bayes," Jurnal Edukasi dan Penelitian Informatika, vol. 4, no. 2, 2018.

[4] Napoleoncat, "Instagram users in IndonesiaNovember 2019," Napoleoncat, [Online]. Available: https://napoleoncat.com/stats/instagram-users-in-indonesia/2019/11. [Accessed 2 Desember 2019].

[5] MySQL, "Full-Text Search Functions," MySQL, [Online]. Available: https://dev.mysql.com/doc/refman/8.0/en/fulltext-search.html. [Accessed 28 November 2019].

[6] I. N. S. Paliwahet, I. M. Sukarsa and I. K. G. D. Putra, "Pencarian Informasi Wisata Daerah Bali menggunakan Teknologi Chatbot," LONTAR KOMPUTER, vol. 8, no. 3, pp. 144-153, December 2017.

[7] M. S. N. P. Dewa Ayu Putri Wulandari, "Pemanfaatan Big Data Media Sosial Dalam Menganalisa Kemenangan Pilkada," Majalah Ilmiah Teknologi Elektro, vol. 18, no. 1, 2019.

[8] P. S. M. Suryani, L. Linawati and K. O. Saputra, "Penggunaan Metode Naïve Bayes Classifier pada Analisis Sentimen Facebook Berbahasa Indonesia," Majalah Ilmiah Teknologi Elektro, vol. 18, no. 1, 2019.

[9] K. A. B. Permana, MadeSudarma and W. G. Ariastina, "Analisis Rating Sentimen pada Video di Media Sosial Youtube Menggunakan STRUCTSVM," Majalah IlmiahTeknologi Elektro, vol. 18, no. 1, 2019.

[10] V. A. Kharde and S. Sonawane, "Sentiment Analysis of Twitter Data: A Survey of Techniques," International Journal of Computer Applications, vol. 139, no. 11, 2016.

p-ISSN:1693 - 2951; e-ISSN: 2503-2372 
[11] B. Nandi, M. Ghanti and S. Paul, "Text Based Sentiment Analysis," in Proceedings of the International Conference on Inventive Computing and Informatics, India, 2017.

[12] X. Fan, "Text Sentiment Analysis: A Review," in IEEE 4th International Conference on Computer and Communications, Beijing,, 2018.

[13] A. T. J. Harjanta, "Preprocessing Text untuk Meminimalisir Kata yang Tidak Berarti dalam Proses Text Mining," Jurnal Informatika Upgris, vol. 1, no. 11, 2015.

[14] R. Melita, V. Amrizal, H. B. Suseno and T. Dirjam, "Penerapan Metode Term Frequency Inverse Document Frequency (TF-IDF) dan Cosine Similarity pada Sistem Temu Kembali Informasi untuk Mengetahui Syarah Hadits Berbasis Web (Studi Kasus: Syarah Umdatil Ahkam)," Jurnal Teknik Informatika, vol. 11, no. 2, 2018.

[15] S. Qaiser and R. Ali, "Text Mining: Use of TF-IDF to Examine the Relevance of Words to Documents," International Journal of Computer Applications, vol. 181, no. 1, 2018.

[16] D. Wahyuningsih and S. E. T. Sami, "Pengembangan Smartphone Book dengan Metode Pattern Matching," Jurnal Ilmiah KOMPUTASI, vol. 16, no. $2,2017$. 